\title{
Constraints on PSC particle microphysics derived from lidar observations
}

\author{
Li Liua ${ }^{a}$ Michael I. Mishchenko ${ }^{\text {b,* }}$ \\ ${ }^{2}$ Department of Earth and Environmental Sciences, Columbia University, and NASA GISS, 2880 \\ Broadway, New York, NY 10025, USA \\ ${ }^{\mathrm{b}}$ Goddard Institute for Space Studies, 2880 Broadway, New York, NY 10025, USA
}

\begin{abstract}
Based on extensive $T$-matrix computations of light scattering by polydispersions of randomly oriented, rotationally symmetric nonspherical particles, we analyze existing lidar observations of polar stratospheric clouds (PSCs) and derive several constraints on PSC particle miscrophysical properties. We show that sharp-edged nonspherical particles (finite circular cylinders) exhibit less variability of lidar backscattering characteristics with particle size and aspect ratio than particles with smooth surfaces (spheroids). For PSC particles significantly smaller than the wavelength, the backscatter color index $\alpha$ and the depolarization color index $\beta$ are essentially shape-independent. Observations for type Ia PSCs can be reproduced by spheroids with aspect ratios larger than 1.2, oblate cylinders with diameter-to-length ratios greater than 1.6, and prolate cylinders with length-to-diameter ratios greater than 1.4. The effective equalvolume-sphere radius for type Ia PSCs is about $0.8 \mu \mathrm{m}$ or larger. Type Ib PSCs are likely to be composed of spheres or nearly spherical particles with effective radii smaller than $0.8 \mu \mathrm{m}$. Observations for type II PSCs are consistent with large ice crystals (effective radius greater than $1 \mu \mathrm{m})$ modeled as cylinders or prolate spheroids.

Keywords: Scattering, Depolarization, Polar stratospheric clouds, Remote sensing, Nonspherical particles
\end{abstract}

*Corresponding author. Tel.: +1 212678 5590; fax: +1 2126785622.

E-mail address: crmim@giss.nasa.gov 


\section{Introduction}

Although polar stratospheric clouds (PSCs) are unlikely to cause a significant direct radiative forcing of climate, their critical role in chemical ozone depletion is now well recognized (e.g., [1] and references therein). A detailed review of PSC studies has recently been published by Toon et al. [2]. The traditional classification of PSC types is based on lidar observations [3]. Type Ia PSCs are characterized by low backscattering but strong depolarization, whereas type Ib PSCs exhibit the opposite behavior. Type II PSCs demonstrate both strong backscatter and large depolarization ratios. Type Ib clouds are believed to consist of droplets of supercooled ternary solutions (STSs) of water, nitric acid, and sulfuric acid [4], whereas type Ia PSCs are thought to form by condensation of nitric acid tri- or dihydrate (NAT or NAD). Type II PSCs are thought to consist of water ice crystals. Although more recent lidar observations indicate the occurrence of other types of PSCs (e.g., [5]-[9]), the traditional classification covers the majority of PSC observations (e.g., [10]) and is, therefore, the focus of this paper.

Our aim is to derive certain constraints on PSC particle microphysics based solely on remote-sensing lidar observations. Although these constraints may not always provide a definitive identification of the shape, size, and composition of PSC particles, they can significantly narrow down the plausible range of particle microphysical parameters and can be useful in analyses of in situ physical and chemical measurements as well as in modeling PSC particle formation and evolution.

Analyzing lidar observations of PSCs is a challenging problem because many PSCs are likely to consist of nonspherical solid particles with sizes comparable to the wavelength of the lidar light (at least for lidars operating in the visible and near-infrared spectral ranges). Theoretical computations of lidar backscatter and depolarization by wavelength-sized 
nonspherical particles may not rely on the geometrical optics approximation $[11,12]$ but must be based on directly solving the Maxwell equations using an exact numerical technique [13]. Although techniques such as the finite difference time domain method (FDTDM; $[14,15])$ and the discrete dipole approximation (DDA; [16]) have no restrictions on the particle shape, their relatively low efficiency and limited size parameter range make their application to polydispersions of randomly oriented PSC particles problematic. Therefore, we base our analysis on the $T$-matrix code [17] specifically designed for polydisperse, randomly oriented, rotationally symmetric particles such as spheroids and finite circular cylinders. The code takes advantage of the analytical procedure for averaging scattering and absorption characteristics over the uniform distribution of particle orientations $[18,19]$, uses the matrix inversion scheme baser on a special form of the LU-factorization method [20], and extends the range of particle size parameters by employing extended-precision floating-point FORTRAN variables [21]. Although the code is limited to rotationally symmetric particle shapes, it is much faster and is applicable to significantly larger size parameters than FDTDM and DDA. Furthermore, by changing the aspect ratio of spheroids and the length-to-diameter ratio of circular cylinders one can model a wide variety of oblate and prolate shapes with either smooth or sharp-edged surfaces.

\section{2. $T$-matrix computations}

Assuming that the laser light is linearly polarized, we define the linear backscattering depolarization ratio $\delta(\lambda)$ at the lidar wavelength $\lambda$ as the ratio of the aerosol backscatter returns in the perpendicular, $\beta_{a \perp}(\lambda)$, and parallel, $\beta_{a / l}(\lambda)$, planes relative to the emitted polarization plane:

$$
\delta(\lambda)=\frac{\beta_{a \perp}(\lambda)}{\beta_{a / l}(\lambda)}
$$


[22-24]. The backscatter ratio $R(\lambda)$ is defined as the ratio of the total molecular, $\beta_{m}(\lambda)$, and aerosol, $\beta_{a}(\lambda)$, backscatter returns to the molecular backscatter return [3]:

$$
R(\lambda)=\frac{\beta_{m}(\lambda)+\beta_{a}(\lambda)}{\beta_{m}(\lambda)}
$$

Similarly, the aerosol backscatter ratio is given by

$$
R_{a}(\lambda)=\frac{\beta_{a}(\lambda)}{\beta_{m}(\lambda)}=R(\lambda)-1
$$

The color ratio $S\left(\lambda_{2}, \lambda_{1}\right)$ is defined as the ratio of the aerosol backscatter ratios at wavelengths $\lambda_{2}$ and $\lambda_{1}$ :

$$
S\left(\lambda_{2}, \lambda_{1}\right)=\frac{R_{a}\left(\lambda_{2}\right)}{R_{a}\left(\lambda_{1}\right)}
$$

The wavelength dependence of the aerosol backscatter is often characterized by the backscatter color index

$$
\alpha=4-\frac{\ln S\left(\lambda_{2}, \lambda_{1}\right)}{\ln \left(\lambda_{2} / \lambda_{1}\right)}
$$

Analogously, the wavelength dependence of the depolarization ratio is described by the depolarization color index

$$
\beta=-\frac{\ln \left[\delta\left(\lambda_{2}\right) / \delta\left(\lambda_{1}\right)\right]}{\ln \left(\lambda_{2} / \lambda_{1}\right)}
$$

It is thus assumed that the aerosol backscatter $\beta_{a}$ is proportional to $\lambda^{-\alpha}$ (given the $\lambda^{-4}$ dependence of the molecular backscatter) and the depolarization ratio $\delta$ is proportional to $\lambda^{-\beta}$. A positive $\alpha(\beta)$ indicates that the aerosol backscatter (depolarization ratio) decreases with increasing wavelength [25]. A large $\alpha$ indicates the abundance of particles with radii smaller than the lidar wavelengths, whereas a small $\alpha$ indicates the predominance of large particles $[2,6]$. The depolarization ratio vanishes for molecular scattering and spherical particles. A 
nonzero $\delta$ usually indicates the presence of nonspherical particles provided that the contribution of multiple scattering to the detected signal is negligible $[23,24,26]$. (Note, however, that wavelength-sized needlelike and platelike particles can generate depolarization ratios close to zero [27]).

The lidar scattering properties of particles depend upon the lidar wavelengths as well as on the particle size distribution, shape, and refractive index. We model the shape of nonspherical PSC particles using smooth spheroids with varying aspect ratios and sharp-edged circular cylinders with varying length-to-diameter ratios. Previous analyses of PSC observations assumed different analytical representations of the particle size distribution, including gamma and log normal distributions. However, it has been demonstrated by Hansen and Travis [28] that many size distributions can be well represented by just two parameters, the effective radius $r_{\text {eff }}$ and effective variance $v_{\text {eff }}$. Specifically, they have shown that different size distributions but with the same $r_{\text {eff }}$ and $v_{\text {eff }}$ can be expected to have similar scattering properties. In this study, we have adopted a simple power law distribution given by

$$
n(r)=\left\{\begin{array}{l}
C \text { for } r \leq r_{1}, \\
C\left(r_{1} / r\right)^{3} \text { for } r_{1} \leq r \leq r_{2}, \\
0 \text { for } r>r_{2},
\end{array}\right.
$$

where $C$ is a normalization constant and $r$ is the radius of the volume-equivalent sphere. The parameters $r_{1}$ and $r_{2}$ are chosen such that the effective variance is fixed at 0.1 , representing a moderately wide distribution. An important advantage of the power law distribution is that for the same $v_{\text {eff }}$, it has a (much) smaller value of the maximal radius $r_{2}$ than optically equivalent gamma and log normal distributions, thereby significantly accelerating theoretical computations [29].

Most of our theoretical computations pertain to two typical lidar wavelengths of $603 \mathrm{~nm}$ and 
$1064 \mathrm{~nm}$ and assume a spectrally independent refractive index. Measurements by Deshler et al. [30] showed that the refractive index of PSC particles at visible and near-infrared wavelengths was close to $1.47 \pm 0.01$ in the lower nondepolarizing layer of the cloud and $1.52-1.56 \pm 0.04$ in the upper depolarizing layer. These values are in reasonable agreement with those reported by Middlebrook et al. [31] and Berland et al. [32]. A typical value of the refractive index of water ice at visible and near-infrared wavelengths is 1.308 [33]. Based on this evidence, we chose the refractive indices 1.5 and 1.308 as typical of type I and II PSC particles, respectively. We thus used the same refractive index for type Ia and Ib PSCs, the reason being that their refractive indices appear to be close and that their chemical composition remains to be somewhat uncertain. The computations have been performed for the range $0-3 \mu \mathrm{m}$ of effective radii for prolate and oblate spheroids with aspect ratios from 1 to 2 , prolate cylinders with length-todiameter ratios from 1 to 2 , and oblate cylinders with diameter-to-length ratios from 1 to 2 .

\section{Observational data}

Table 1 summarizes the results of lidar observations of PSCs at $\lambda_{1}=603 \mathrm{~nm}$ and $\lambda_{2}=1064 \mathrm{~nm}$ performed by Browell et al. [3] during the NASANOAA Airborne Arctic Stratospheric Expedition in the winter of 1988-1989. Larsen et al. [34] performed extensive aircraft observations of type I PSCs during the winters of 1989, 1990, 1995, and 1996 and concluded that the color ratio $S(940 \mathrm{~nm}, 480 \mathrm{~nm})$ was greater than 10 for type Ia PSCs and was in the range 5-8 for type Ib PSCs. The range of the color ratio $S(940 \mathrm{~nm}, 490 \mathrm{~nm})$ observed by Vömel et al. [34] for type II PSCs was 11-15.

The backscatter ratio defined by Eq. (2) depends on the PSC particle number concentration. Since the latter cannot be directly retrieved from lidar measurements and is a priori unknown, 
we have not used the measurements of the backscatter ratio in our analysis. Unlike $R$, the backscatter color index, the depolarization ratio, and the depolarization color index are independent of the particle number concentration and can be directly used to infer particle microphysical characteristics. We have converted the color ratio values measured by Larsen et al. [34] and Vömel et al. [35] into the respective backscatter color index values and combined the latter with the measurements by Browell et al. [3]. Table 2 summarizes the ranges of the lidar quantities $\alpha, \delta$, and $\beta$ used in our analysis. Note that instead of using a constant $\beta$ value equal to zero for type Ia and II PSCs, we allowed it to vary within a narrow range $[-0.4,0.4]$, which seems to be a reasonable assumption given the natural variability of PSC particles. The same approach was used tc define the plausible range of variability of the backscatter color index for type 1a PSCs.

\section{Analysis results}

Figures $1-4$ summarize the results of the $T$-matrix computations. In general, the curves of all backscattering characteristics versus effective equivalent-sphere radius are (much) less aspect-ratio dependent for cylinders than for spheroids. This is not surprising since spheroids with an aspect ratio of one are perfect spheres, whereas cylinders with a length-to-diameter ratio of one are already distinctly nonspherical particles. There is a rapid increase of the depolarization ratio with increasing effective radius from 0 to about $0.5 \mu \mathrm{m}$. Maximal $\delta$ values for most nonspherical particles are observed at effective equal-volume-sphere radii between 0.5 $\mu \mathrm{m}$ and $1.5 \mu \mathrm{m}$. The most notable exception are nearly spherical spheroids, whose depolarization ratio increases with particle size rather monotonically. It is obvious that there is no definitive relationship between the magnitude of depolarization and the degree of particle asphericity [36]. For example, prolate spheroids with as small an aspect ratio as 1.05 (Fig. 1) 
produce depolarization ratios exceeding $65 \%$. The maximal depolarization value $(\sim 70 \%)$ is produced by prolate ice spheroid with an aspect ratio of 1.2 (Fig. 3). The fact that this maximal value is caused by wavelength-sized particles indicates that multiple internal reflections in very large particles as discussed by Liou and Lahore [37] are not the only mechanism generating strong depolarization and not necessarily the mechanism producing maximal depolarization values [22].

In the large-particle limit, both $\alpha$ and $\beta$ are expected to tend to zero for nonabsorbing scatterers. This trend is more visible for cylinders than for spheroids. However, both color indices exhibit a significant degree of variability in the range of sizes studied for cylinders as well as for spheroids. In the Rayleigh limit, $\alpha$ must tend to 4 and $\beta$ must tend to zero. This theoretical behavior is indeed well reproduced by our $T$-matrix computations.

Figures 5-7 show the ranges of the effective equivalent-sphere radius that reproduce the observed values of the respective backscattering characteristics for different particle shapes and refractive indices. To represent a plausible PSC particle, a combination of model size, shape, and refractive index must simultaneously reproduce all observed lidar characteristics.

Figure 5 shows that cylinders with diameter-to-length and length-to-diameter ratios larger than about 1.5 and effective equivalent-sphere radii larger than about $0.8 \mu \mathrm{m}$ are the likely model representatives of type Ia PSC particles. Prolate and oblate spheroids with aspect ratios 1.2 and larger are also acceptable solutions, although the ranges of the effective radius that reproduce all three lidar observables may be narrower than those for the cylinders and may be too shapedependent to be realistic.

Figure 6 suggests that type Ib PSC particles are likely to have effective radii less that $0.8 \mu \mathrm{m}$ and are best represented by spheres or spheroids with very small aspect ratios. Spheroids with aspect ratios larger than 1.1 and cylinders may also qualify, but must have radii smaller than a 
few tenths of a micrometer. Note, however, that choosing the narrower range $[2,3]$ of $\alpha$ values observed by Browell et al. [3] would constrain type Ib PSC particles to spheres or nearly spherical spheroids with effective radii close to $0.5 \mu \mathrm{m}$ (cf. [2]).

According to Fig. 7, type II PSC particles are well represented by ice cylinders and prolate spheroids $(\varepsilon \geq 1.2$ ) with effective equivalent-sphere radii exceeding $1 \mu \mathrm{m}$. Although oblate ice spheroids with $\varepsilon=1.1,1.2$, and 1.6 are also potential candidates, the respective effective radius ranges appear to be too narrow to be realistic.

\section{Concluding remarks}

We have used the current advanced version of the $T$-matrix method to perform massive computations of backscattering lidar characteristics for polydisperse, randomly oriented spheroids and circular cylinders and analyzed the existing lidar measurements of three predominant types of PSCs. Our analysis is an extension of that previously published by Toon et al. [2] and determines the likely ranges of particle physical parameters that reproduce the existing lidar data. We have not discussed the plausibility of our results from the standpoint of the physics and chemistry of PSC formation and evolution and hope that such a discussion will be the subject of further research.

An obvious limitation of our analysis is the use of simple, rotationally symmetric shapes and a restricted range of particle sizes. Although our model shapes and the range of effective radii from 0 to $3 \mu \mathrm{m}$ may be relevant to many real PSCs, further effort is obviously warranted in order to include particles with larger sizes (e.g., [38]) and more irregular shapes (e.g., [14]). Another desirable extension would be an analysis of less frequently encountered types of PSCs potentially composed of a mixture of different particle species [2]. 


\section{Acknowledgement}

This research was funded by the NASA Global Aerosol Climatology Project managed by Donald Anderson. 


\section{References}

[1] Carslaw KS, Wirth M, Tsias A, Luo BP, Dörnbrack A, Leutbecher M, Volkert H, Renger W, Bacmeister JT, Reimer E, Peter Th. Increased stratospheric ozone depletion due to mountain-induced atmospheric waves. Nature 1998; 391: 675-678.

[2] Toon OB, Tabazadeh A, Browell EV, Jordan J. Analysis of lidar observations of Arctic polar stratospheric clouds during January 1989. J Geophys Res 2000; 105: 20589-20615.

[3] Browell EV, Butler CF, Ismail S, Robinette PA, Carter AF, Higdon NS, Toon OB, Schoeberl MR, Tuck AF. Airborne lidar observations in the wintertime Arctic stratosphere: polar stratospheric clouds. Geophys Res Lett 1990; 17: 385-388.

[4] Carslaw KS, Luo BP, Clegg SL, Peter Th, Brimblecombe P, Crutzen PJ. Stratospheric aerosol growth and $\mathrm{HNO}_{3}$ gas phase depletion from coupled $\mathrm{HNO}_{3}$ and water uptake by liquid particles. Geophys Res Lett 1994; 21: 2479-2482.

[5] Stefanutti L, Morandi M, Del Guasta M, Godin S, David C. Unusual PSCs observed by LIDAR in Antarctica. Geophys Res Lett 1995; 22: 2377-2380.

[6] Shibata T, Iwasaka Y, Fujiwara M, Hayashi M, Nagatani M, Shiraishi K, Adachi H, Sakai T, Susumu K, Nakura Y. Polar stratospheric clouds observed by lidar over Spitsbergen in the winter of 1994/1995: liquid particles and vertical "sandwich" structure. J Geophys Res 1997; 102: 10829-10840.

[7] Rosen JM, Kjome NT, Larsen N, Knudsen BM, Kyrö E, Kivi R, Karhu J, Neuber R, Beninga I. Polar stratospheric cloud threshold temperatures in the 1995-1996 arctic vortex. J Geophysics Res 1997; 102: 28195-28202.

[8] Tsias A, Wirth M, Carslaw KS, Biele J, Mehrtens H, Reichardt J, Wedekind C, Weiß V, Renger W, Neuber R, von Zahn U, Stein B, Santacesaria V, Stefanutti L, Fierli F, Bacmeister J, Peter T. Aircraft lidar observations of an enhanced type Ia polar stratospheric cloud during APE-POLECAT. J Geophys Res 1999; 104: 23961-23969.

[9] Reichardt J, Tsias A, Behrendt A. Optical properties of PSC Ia-enhanced at UV and visible wavelengths: model and observations. Geophys Res Lett 2000; 27: 201-204.

[10] David C, Bekki S, Godin S, Mégie G, Chipperfield MP. Polar stratospheric clouds climatology over Dumont d'Urville between 1989 and 1993 and the influence of volcanic 
aerosols on their formation. J Geophys Res 1998; 103: 22163-22180.

[11] Macke A, Mishchenko MI, Muinonen K, Carlson BE. Scattering of light by large nonspherical particles: Ray tracing approximation versus T-matrix method. Opt Lett 1995; 20: 1934-1936.

[12] Liou KN, Takano Y, Yang P. Light scattering and radiative transfer in ice crystal clouds: applications to climate research. In Mishchenko MI, Hovenier JW, Travis LD, editors. Light scattering by nonspherical particles: theory, measurements, and applications. San Diego: Academic Press, San Diego, 2000, p. 417-449.

[13] Mishchenko MI, Hovenier JW, Travis LD, editors. Light scattering by nonspherical particles: theory, measurements, and applications. San Diego: Academic Press, 2000.

[14] Yang P, Liou KN. Finite difference time domain method for light scattering by nonspherical and inhomogeneous particles. In Mishchenko MI, Hovenier JW, Travis LD, editors. Light scattering by nonspherical particles: theory, measurements, and applications. San Diego: Academic Press, San Diego, 2000, p. 173-221.

[15] Sun W, Fu Q, Chen Z. Finite-difference time-domain solution of light scattering by dielectric particles with a perfectly matched layer absorbing boundary condition. Appl Opt 1999; 38: $3141-3151$.

[16] Draine BT. The discrete dipole approximation for light scattering by irregular targets. In Mishchenko MI, Hovenier JW, Travis LD, editors. Light scattering by nonspherical particles: theory, measurements, and applications. San Diego: Academic Press, San Diego, 2000, p. 131-145.

[17] Mishchenko MI, Travis LD. Capabilities and limitations of a current Fortran implementation of the T-matrix method for randomly oriented, rotationally symmetric scatterers. J Quant Spectrosc Radiat Transfer, 1998; 60: 309-324.

[18] Mishchenko MI. Light scattering by randomly oriented axially symmetric particles. J Opt Soc Am A 1991; 8: 871-882. [Errata: 9: 497 (1992).]

[19] Mishchenko MI. Light scattering by size-shape distributions of randomly oriented axially symmetric particles of a size comparable to a wavelength. Appl Opt 1993; 32: 4652-4666.

[20] Wielaard DJ, Mishchenko MI, Macke A, Carlson BE. Improved T-matrix computations for large, nonabsorbing and weakly absorbing nonspherical particles and comparison with geometrical-optics approximation. Appl Opt 1997; 36: 4305-4313. 
[21] Mishchenko MI, Travis LD. T-matrix computations of light scattering by large spheroidal particles. Opt Commun 1994; 109: 16-21.

[22] Mishchenko MI, Hovenier JW. Depolarization of light backscattered by randomly oriented nonspherical particles. Opt Lett 1995; 20: 1356-1358.

[23] Gobbi GP. Polarization lidar returns from aerosols and thin clouds: a framework for the analysis. Appl Opt 1998; 37: 5505-5508.

[24] Sassen K. Lidar backscatter depolarization technique for cloud and aerosol research. In Mishchenko MI, Hovenier JW, Travis LD, editors. Light scattering by nonspherical particles: theory, measurements, and applications. San Diego: Academic Press, San Diego, 2000, p. $393-416$.

[25] Toon OB, Browell EV, Kinne S, Jordan J. An analysis of lidar observations of polar stratospheric clouds. Geophys Res Lett 1990; 17 393-396.

[26] Sassen K. The polarization lidar technique for cloud research: a review and current assessment. Bull Am Meteorol Soc 1991; 72: 1848-1866.

[27] Zakharova NT, Mishchenko MI. Scattering properties of needlelike and platelike ice spheroids with moderate size parameters. Appl Opt 2000; 39: 5052-5057.

[28] Hansen JE, Travis LD. Light scattering in planetary atmosphere. Space Sci Rev 1974; 16: $527-610$.

[29] Mishchenko MI and Travis LD. Light scattering by polydispersions of randomly oriented spheroids with sizes comparable to wavelengths of observation. Appl Opt 1994; 33: 72067225 .

[30] Deshler T, Nardi B, Adriani A, Cairo F, Hansen G, Fierli F, Hauchecorne A, Pulvirenti L. Determining the index of refraction of polar stratospheric clouds above Andoya $\left(69^{\circ} \mathrm{N}\right)$ by combining size-resolved concentration and optical scattering measurements. J Geophys Res 2000; 105: 3943-3953.

[31] Middlebrook AM, Berland BS, George SM, Tolbert MA, Toon OB. Real refractive indices of infrared-characterized nitric-acid/ice films: implications for optical measurements of polar stratospheric clouds. J Geophys Res 1994; 99: 25655-25666.

[32] Berland BS, Haynes DR, Foster KL, Tolbert MA, George SM, Toon OB. Refractive indices 
of amorphous and crystalline $\mathrm{NHO}_{3} / \mathrm{H}_{2} \mathrm{O}$ films representative of polar stratospheric clouds. J Phys Chem 1994; 98: 4358-4364.

[33] Warren SG. Optical constants of ice from the ultraviolet to the microwave. Appl Opt 1984; 23: 1206-1225.

[34] Larsen N, Knudsen BM, Rosen JM, Kjome NT, Neuber R, Kyrö E. Temperature histories in liquid and solid polar stratospheric cloud formation. J Geophys Res 1997; 102; 2350523517.

[35] Vömel H, Rummukainen M, Kivi R, Karhu J, Turunen T, Kyrö E, Rosen J, Kjome N, Oltmans S. Dehydration and sedimentation of ice particles in the Arctic stratospheric vortex. Geophys Res Lett 1997; 24: 795-798.

[36] Mishchenko MI, Sassen K. Depolarization of lidar returns by small ice crystals: an application to contrails. Geophys Res Lett 1998; 25: 309-312.

[37] Liou $\mathrm{KN}$, Lahore $\mathrm{H}$. Laser sensing of cloud composition: a backscatter depolarization technique. J Appl Meteorol 1974; 13: 257-263.

[38] Goodman J, Verma S, Pueschel RF, Hamill P, Ferry GV, Webster D. New evidence of size and composition of polar stratospheric cloud particles. Geophys Res Lett 1997; 24: 615618. 


\section{FIGURE CAPTIONS}

Figure 1. Linear depolarization ratio $\delta(603 \mathrm{~nm})$, backscatter color index $\alpha$, and depolarization color index $\beta$ versus effective equal-volume-sphere radius $r_{\text {eff }}$ for polydisperse, randomly oriented spheroids with a refractive index of $m=1.5 . \varepsilon$ is the ratio of the largest to the smallest semi-axes of a spheroid. The light and dark shaded areas show the observed ranges of these parameters for type Ia and Ib PSCs, respectively.

Figure 2. As in Fig. 1, but for polydisperse, randomly oriented cylinders. The shapes of prolate and oblate cylinders are specified by length-to-diameter and diameter-to-length ratios, respectively.

Figure 3. As in Fig. 1, but for the refractive index $m=1.308$ typical of water ice at visible wavelengths. The shaded areas show the respective ranges of the backscattering characteristics observed for type II PSCs.

Figure 4. As in Fig. 3, but for polydisperse, randomly oriented circular cylinders.

Figure 5. The bars depict the respective ranges of the effective radius that reproduce the values of $\delta, \alpha$, and $\beta$ observed for type Ia PSCs, as shown in Figs. 1 and 2.

Figure 6 . The bars depict the respective ranges of the effective radius that reproduce the values of $\delta$ and $\alpha$ observed for type Ib PSCs, as shown in Figs. 1 and 2.

Figure 7. The bars depict the respective ranges of the effective radius that reproduce the values of $\delta, \alpha$, and $\beta$ observed for type II PSCs, as shown in Figs. 3 and 4. 
Table 1. Typical backscattering characteristics of PSCs observed by Browell et al. [3].

\begin{tabular}{|c|c|c|c|c|c|c|}
\hline \multirow{2}{*}{$\begin{array}{c}\text { Cloud } \\
\text { Type }\end{array}$} & \multicolumn{2}{|c|}{$R$} & \multirow{2}{*}{$\alpha$} & \multicolumn{2}{c|}{$\delta(\%)$} & \multirow{2}{*}{$\beta$} \\
\cline { 5 - 7 } & $\lambda_{1}=603 \mathrm{~nm}$ & $\lambda_{2}=1064 \mathrm{~nm}$ & & $\lambda_{1}=603 \mathrm{~nm}$ & $\lambda_{2}=1064 \mathrm{~nm}$ & \\
\hline Ia & $1.2-1.5$ & $2-5$ & 0.4 & $30-50$ & $30-50$ & $\sim 0$ \\
\hline Ib & $3-8$ & $5-20$ & $2-3$ & $0.5-2.5$ & $<4$ & No data \\
\hline II & $>10$ & $>20$ & $<0.8$ & $>10$ & $>10$ & $\sim 0$ \\
\hline
\end{tabular}

Table 2. Ranges of backscattering characteristics for different PSC types used in this study.

\begin{tabular}{|c|c|c|c|}
\hline Cloud Type & $\alpha$ & $\delta(603 \mathrm{~nm})(\%)$ & $\beta$ \\
\hline Ia & $0-0.8$ & $30-50$ & $-0.4-0.4$ \\
\hline Ib & $1-3$ & $0.5-2.5$ & No data \\
\hline II & $-0.2-0.8$ & $>10$ & $-0.4-0.4$ \\
\hline
\end{tabular}



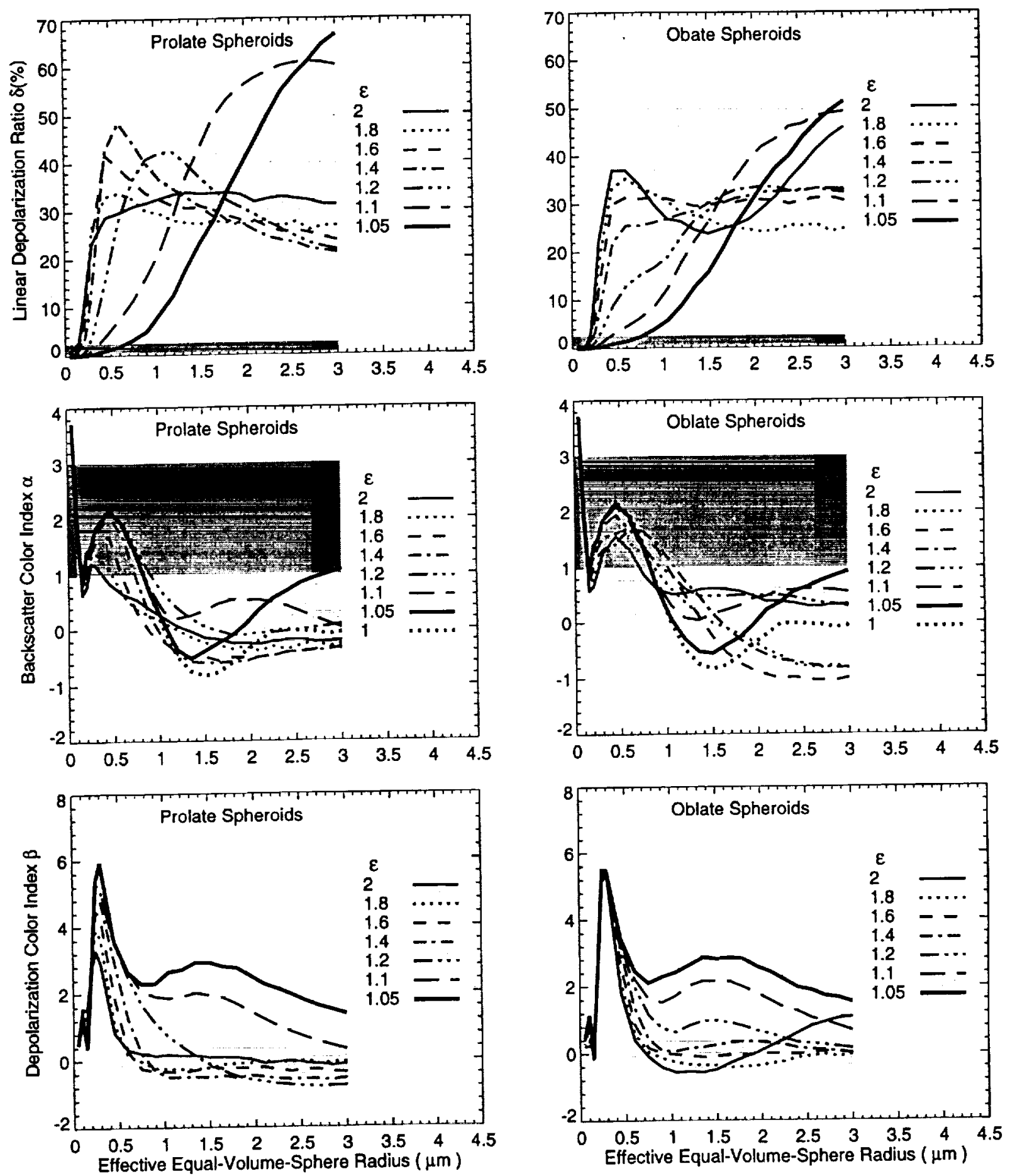

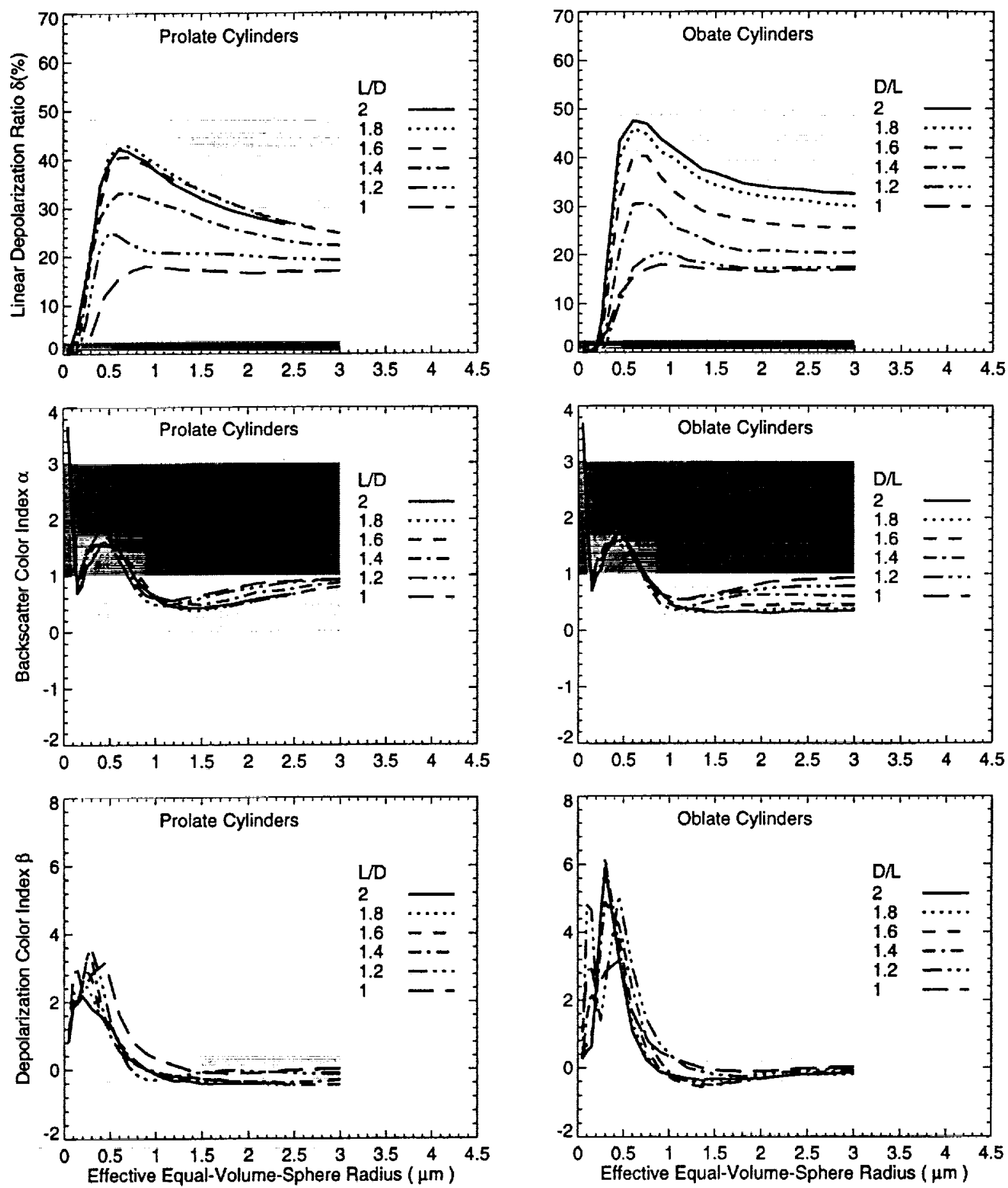

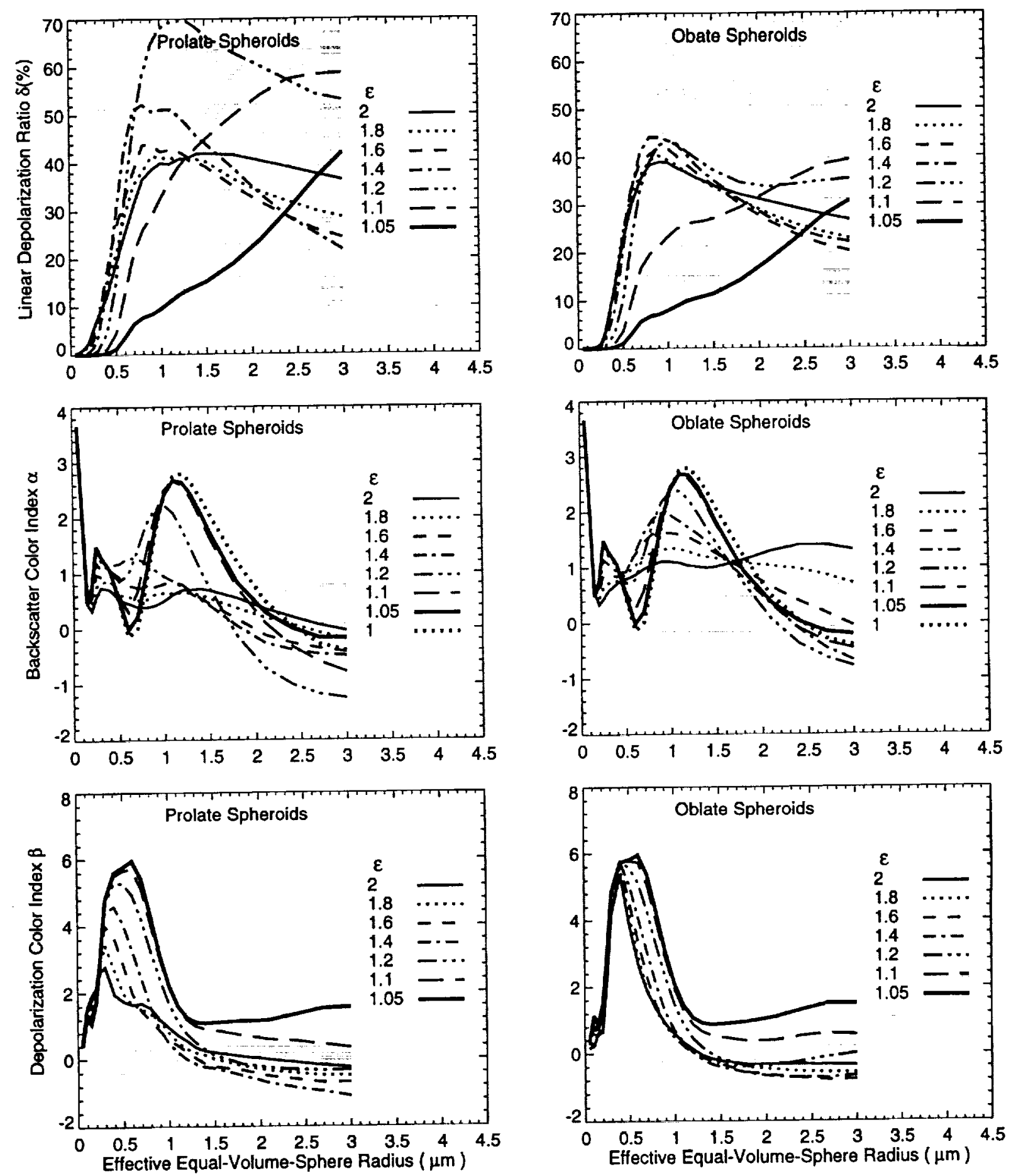

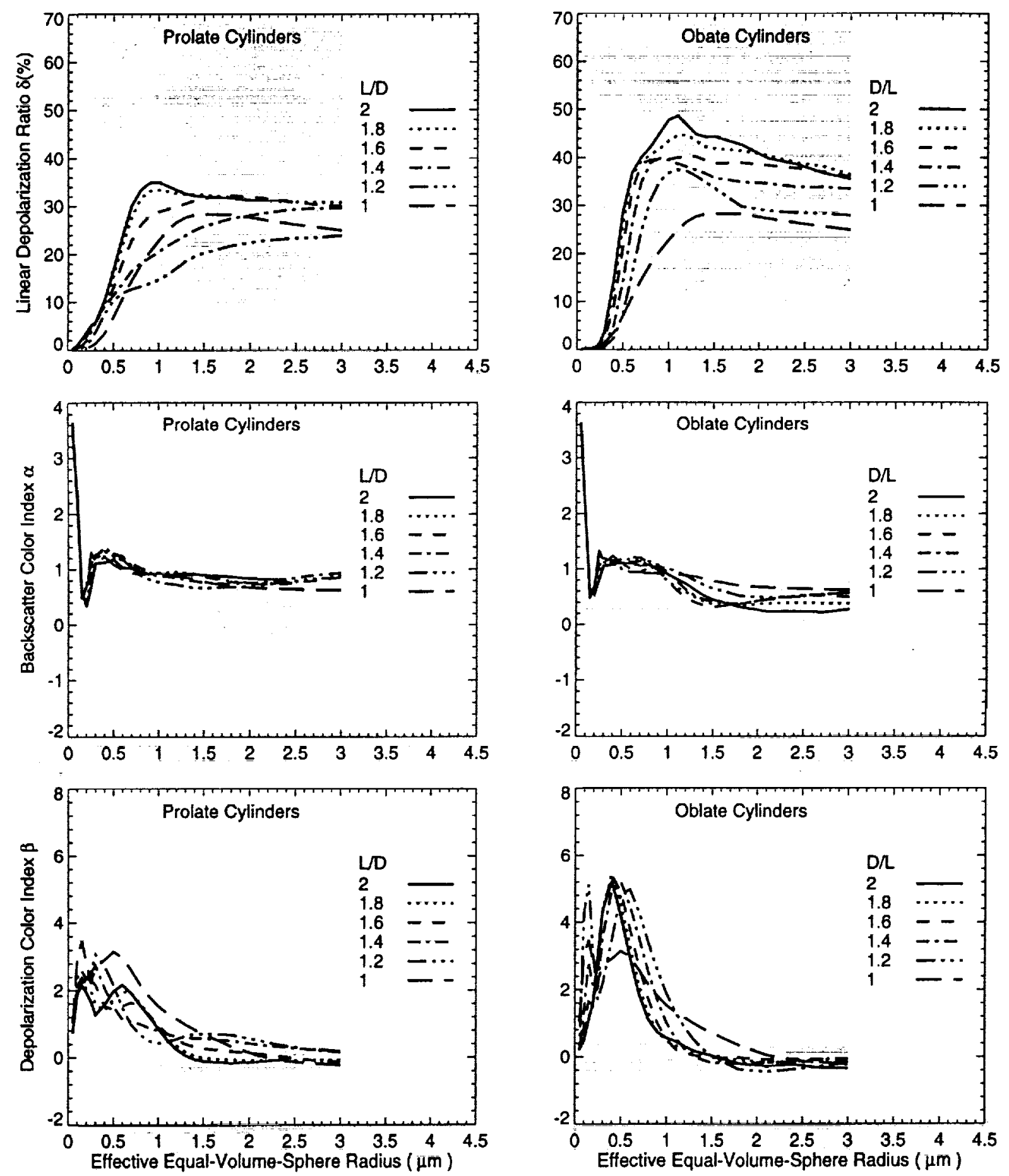

Fig. 4 
Type la PSCs

Prolate Spheroids

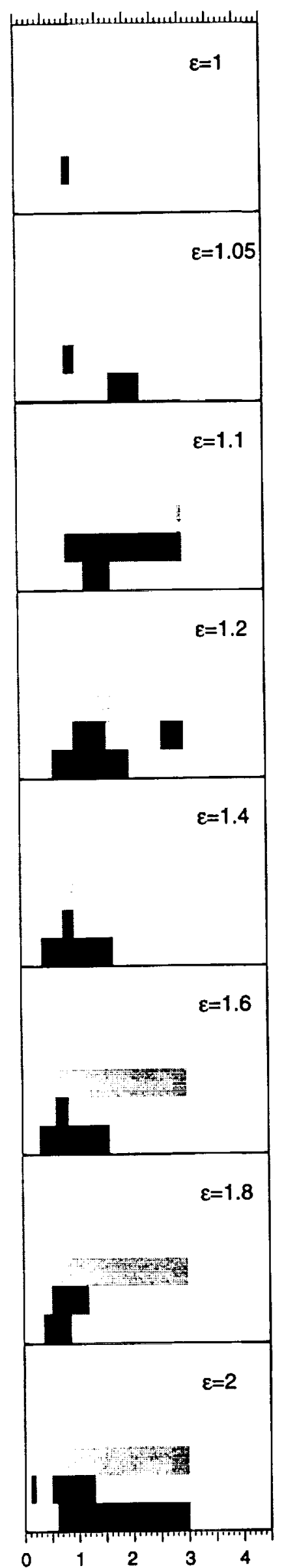

Oblate Spheroids

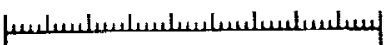

$\varepsilon=1$

$\varepsilon=1.05$

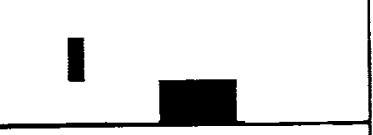

$\varepsilon=1.1$

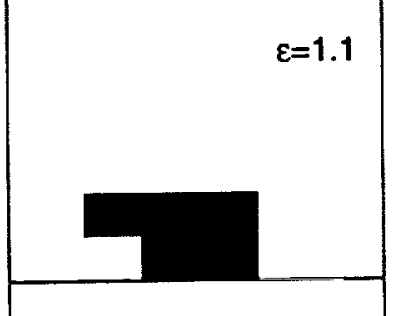

$\varepsilon=1.2$
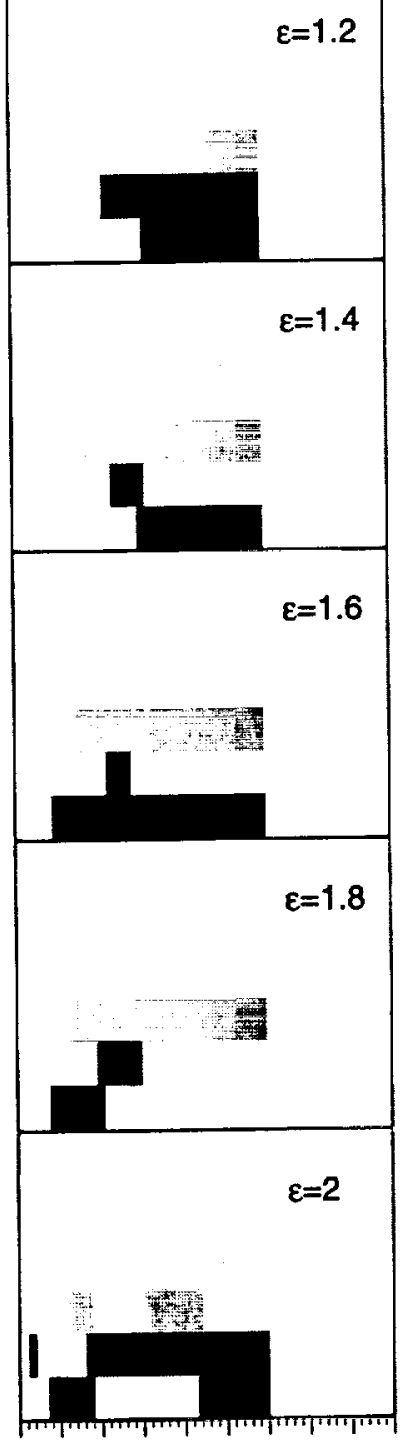

$\begin{array}{lllll}0 & 1 & 2 & 3 & 4\end{array}$
Prolate Cylinders

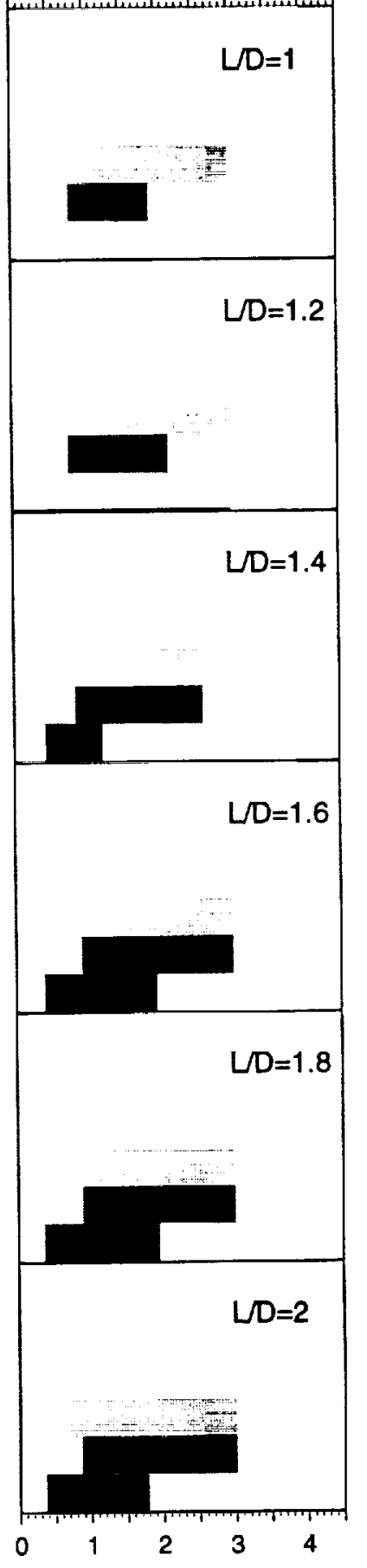

Effective Equal-Volume-Sphere Radius $(\mu \mathrm{m})$

Oblate Cylinders

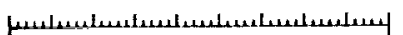

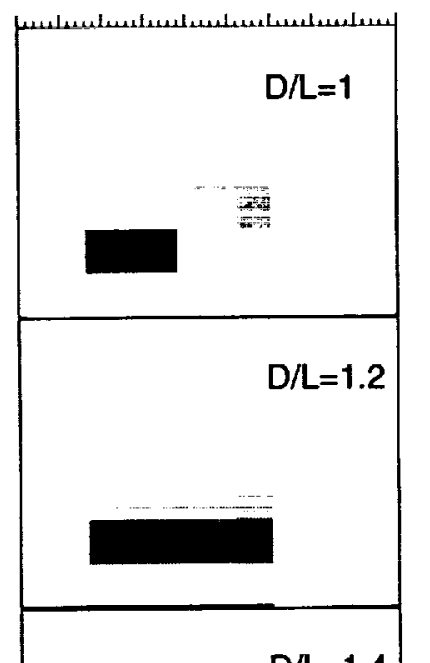

$D / L=1.4$

$\mathrm{D} / \mathrm{L}=1.6$

$D / L=1.8$

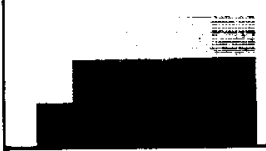

$D / L=2$

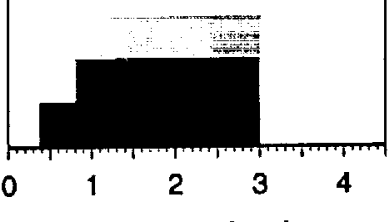

$\delta$

$\alpha$ 
Type Ib PSCs

Prolate Spheroids

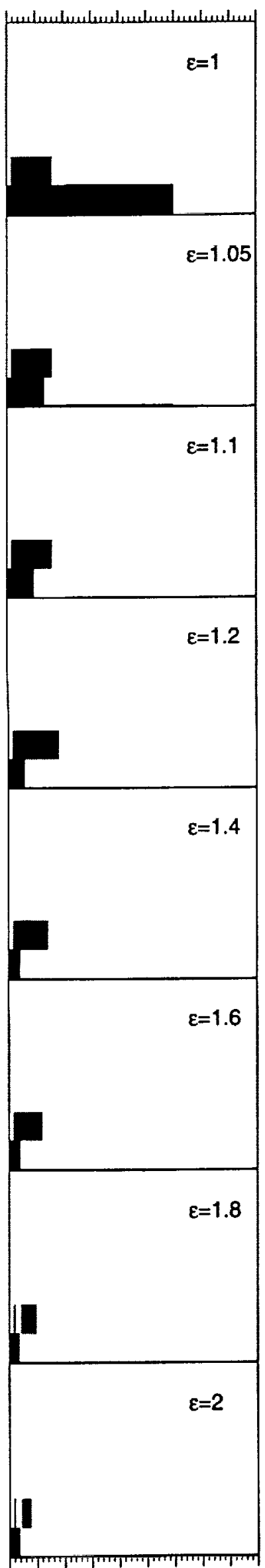

Oblate Spheroids

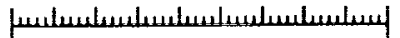

$\varepsilon=1$

$\varepsilon=1.1$

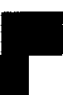

$\varepsilon=1.2$

$\varepsilon=1.4$
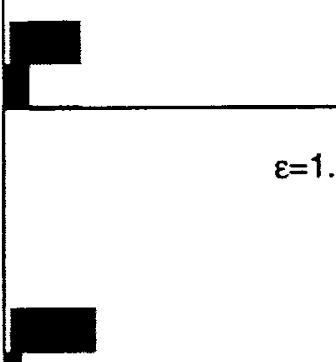

$\varepsilon=1.6$

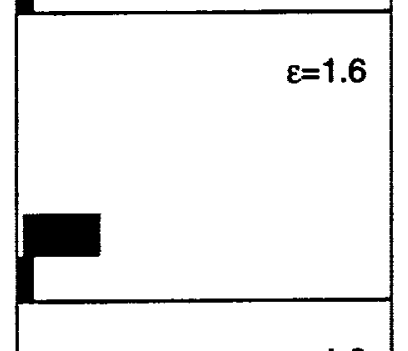

$\varepsilon=1.8$

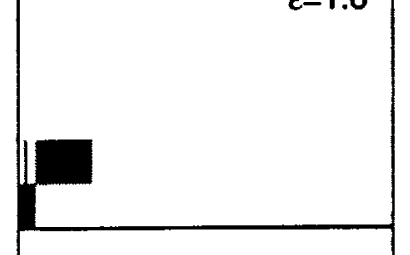

$\varepsilon=2$
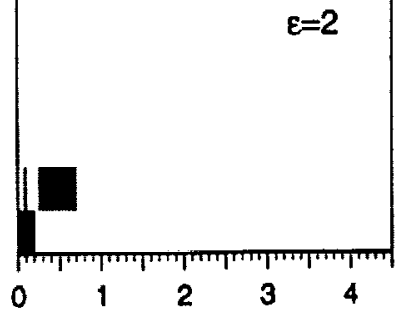

Prolate Cylinders

Oblate Cylinders
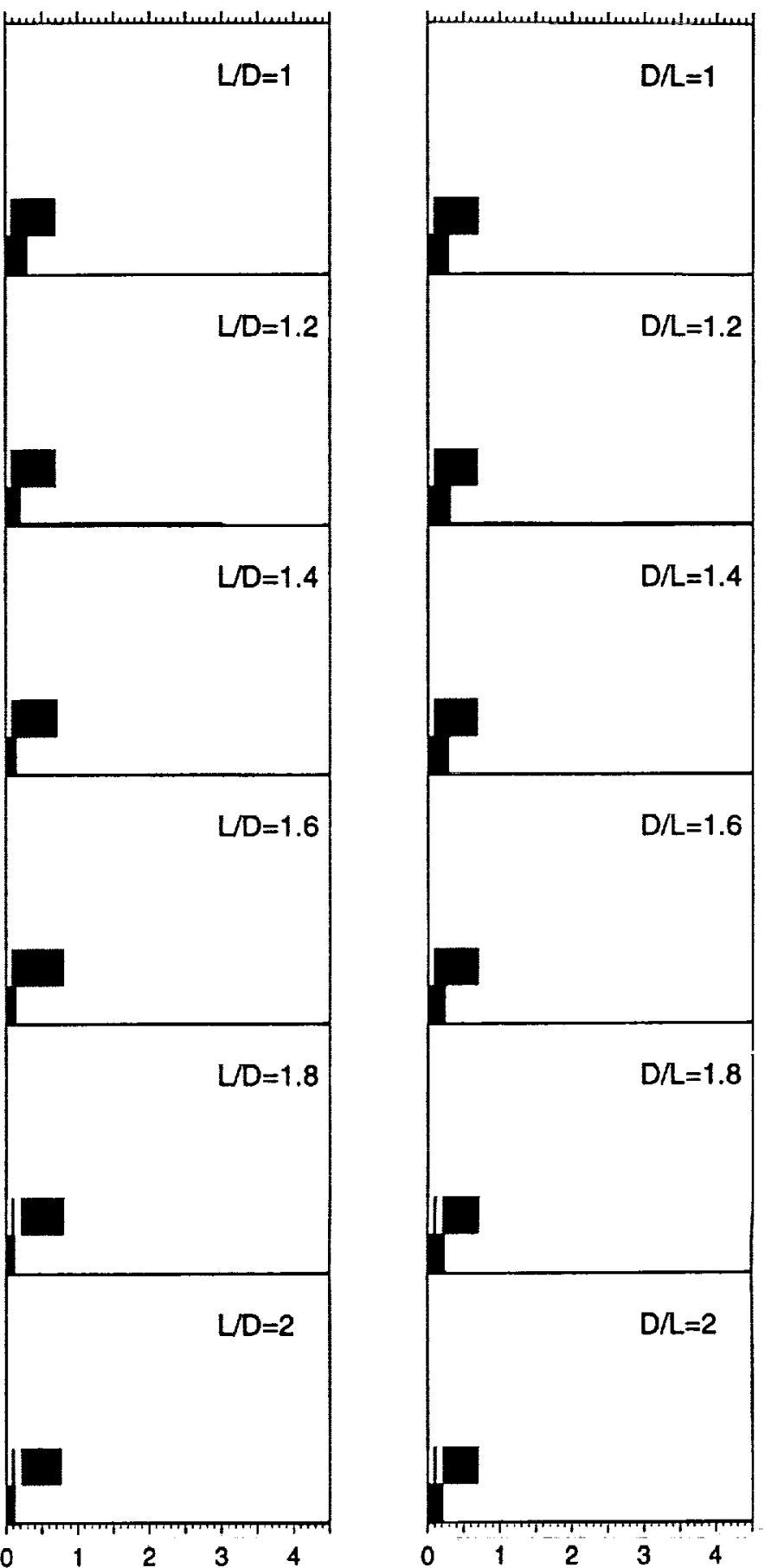

Effective Equal-Volume-Sphere Radius $(\mu \mathrm{m})$ 
'Type II PSCs'

Prolate Spheroids

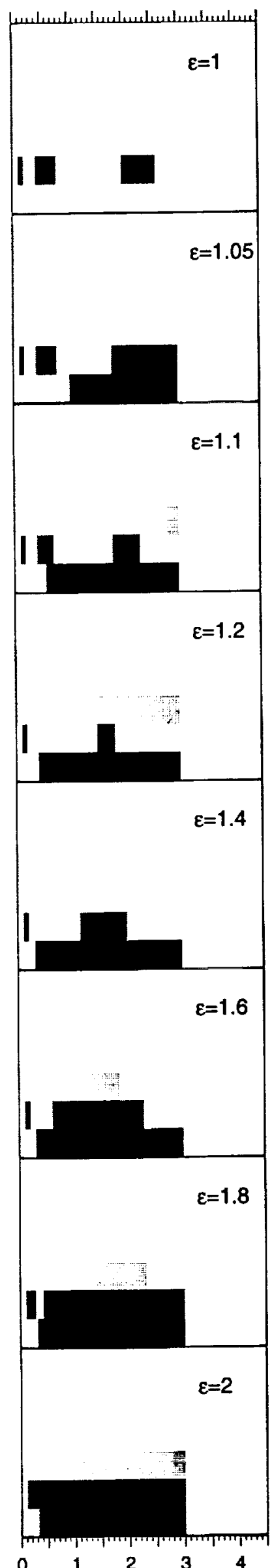

Oblate Spheroids

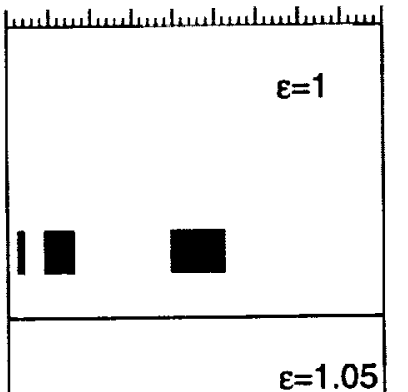

1

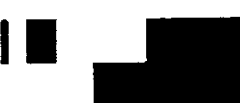

$\varepsilon=1.1$

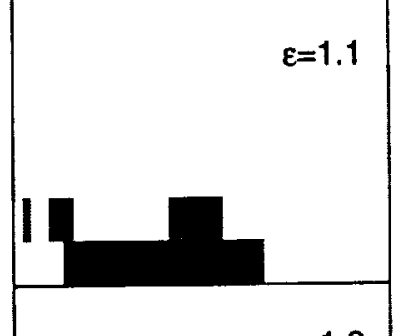

$=1.2$

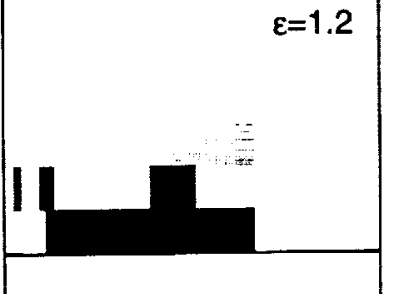

$\varepsilon=1.4$

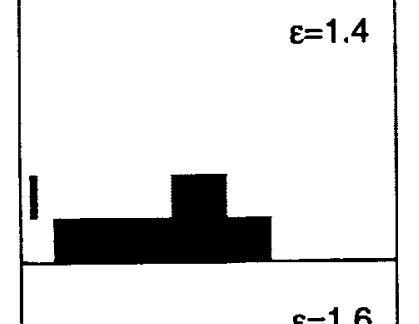

$\varepsilon=1.6$
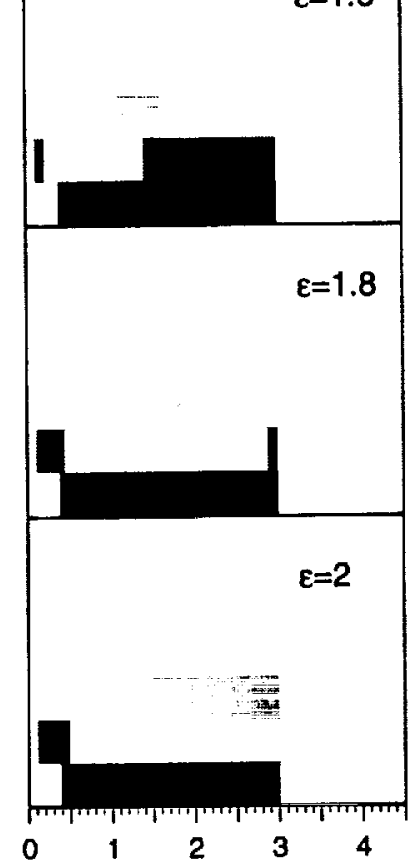

Prolate Cylinders

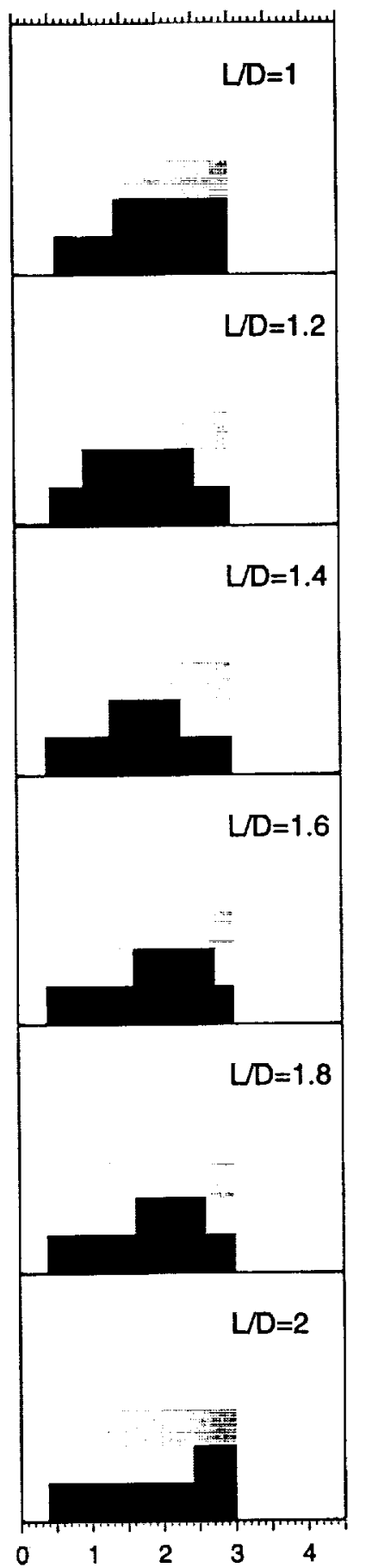

Effective Equal-Volume-Sphere Radius $(\mu \mathrm{m})$
Oblate Cylinders

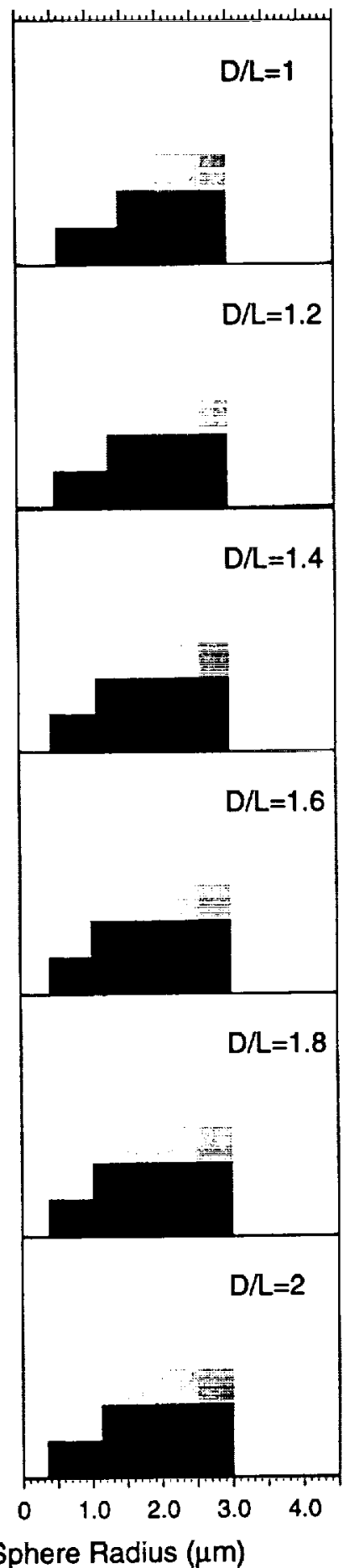

$\alpha$

Effective Equal-Volume-Sphere Radius $(\mu \mathrm{m})$ 
